Journal of Teaching and Learning with Technology, Vol. 7, No. 1, Spring 2018, pp. 43-58.

doi:10.14434/jotlt.v7n1.23346

\title{
“I Got Confused Reading It": Using Backchannels to Collaboratively Build Meaning with Texts
}

\author{
Robyn Seglem \\ Illinois State University \\ rseglem@ilstu.edu \\ Linda Haling \\ University of Wisconsin Oshkosh \\ halingl@uwosh.edu
}

\begin{abstract}
This study explores the use of backchannels, real-time online conversations taking place simultaneously with spoken discussions (the front channel), as one approach to meaning-making through discussion. Using transcripts of front and backchannel discussions, we examine how undergraduate preservice teachers utilize backchannels to talk about class-assigned texts. Although previous research has suggested that backchannels can create distractions, our study found that participants within the backchannel groups were able to create meaning through their interactions. We used five types of talk (analytic, personal, intertextual, transparent, and performative) to aid in our analysis. While we found evidence of all types of talk in the transcripts, analytical talk dominated the conversations, suggesting that backchannels can indeed encourage close readings of texts. In addition, we found that the nature of the online environment created a sixth category of talk. This type of talk, which we called negotiation, allowed participants in the backchannel to define and react to the digital space they interacted within. Findings point to increased engagement in class discussion and the potential of backchannels as a way to effectively integrate technology into instruction.
\end{abstract}

Keywords: online discussion, technology integration, reader response, literacy

Research in new literacies, multiliteracies and digital literacies indicate that literacy practices are rapidly changing (e.g. Cope \& Kalantzis, 2009; Lankshear \& Knobel, 2011; The New London Group, 1996). This understanding, paired with an increased push for technology integration in schools, suggests that teacher educators must explore different approaches for effective teaching with technology if they are to model its use for teacher candidates. Multiple digital tools exist that allow teachers to facilitate the consumption and production of knowledge. In our experiences working with educators, there has been a heavy reliance on student consumption of technology through teacher presentations (i.e PowerPoint or Prezi). However, this approach to technology integration rarely leverages the potential of technology because it simply repackages traditional teacher-centered approaches to instruction and does little to help students develop their own digital literacy skills. For this reason, many researchers have examined the ways teachers and teacher educators have integrated technology into their teaching. Adoption models such as the Replacement, Amplification, and Transformation (RAT) framework (Hughes, Thomas, \& Scharber, 2006) and the Substitution, Augmentation, Modification, Redefinition (SAMR) model (Puentedura, 2006) provide guidance to assist teachers in leveraging technology to significantly 
alter learning rather than simply doing what they have always done with a new tool. Our views on technology integration coincide with models such as these, as we believe that true learning with technology occurs when students become the producers of knowledge via technology. Therefore, we wanted to investigate how to help students use digital tools to create new understandings.

After witnessing the use of social media like Twitter at national conferences, we felt there was potential for learners to construct new understandings about content through collaborative media channels. We also had the opportunity to observe a high school English teacher who used closed chatrooms to facilitate a synchronous discussion of class novels. This process is known as backchanneling because the online discussion is taking place at the same time as a live discussion in the classroom. Anecdotally, the backchannel appeared to serve as a way to engage both the participants at the national conferences and the students in the classroom. Our observations prompted us to examine whether backchannels impact the kinds of meaning students construct using similar digital tools. In this paper, we explore the use of backchannels as one approach to discussion and as a way to produce knowledge. We examine how undergraduate preservice teachers utilize backchannels to make sense of class-assigned texts. In doing so, we explore the potential of backchannels as a way to effectively integrate technology to impact student learning.

\section{Literature Review}

The term backchannel has its roots in the field of linguistics where it refers to the verbal and nonverbal responses provided by the listener during a communication event (Yngve, 1970). In fact, the bulk of research on backchanneling is focused on the linguistic/non-verbal communication, particularly as it relates to second language learners (e.g. Maftoon \& Ziafar, 2013). Separate from the front or main channel where the speaker is relaying information, the backchannel serves as a way for listeners to convey interest or comprehension (White, 1989). In this way, the backchannel acknowledges the dialogic nature of communication, pointing to the importance of the listener in the meaning-making process.

With the advent of technological tools like instant messaging, Twitter, chat rooms, and blogs in recent years, the term backchannel has shifted to describe the conversations that often take place digitally during meetings, presentations, and classroom lectures. Yet, while much writing about backchannels has been done in social media such as blogs (e.g. Mishra, 2008; Shirky, 2002) and traditional media outlets such as The New York Times (Guernsey, 2003) and Time (Johnson, 2009), very little research has been completed to date on digital backchanneling, particularly in terms of the secondary classroom and its educational benefits. Instead, the educational research on backchanneling has focused on classes held in large lecture hall formats (e.g. Aagard, Bowen, \& Olesova, 2010; Jacobs \& McFarlane, 2005; Pohl, Gehlen-Baum, \& Bry, 2011; Schwier \& Seaton, 2013), and little emphasis has been placed on researching backchannels in educational settings and even less on how participants in backchannels construct meaning from texts.

In one unpublished study, Chan, Mitnick, and Yardi (2006) analyzed nearly two years' worth of backchannel data, including more than 200,000 posts from large lecture classes. They found that backchannel posts fell into five categories: comments germane to class material, comments indirectly related to class material, comments about the classroom or those in it, social, and entry/exit. Upon closer examination, the researchers found that backchannels work best for "peer to peer learning and seeking help" (p.26). Participants were motivated by social reinforcement, and there was increased interactivity and discourse. Yet negative experiences were also noted, with "multitasking and cognitive overload” (p. 33) the most prevalent. 
The majority of research on digital backchannels in large settings explores the specific platforms for computer-mediated communication, such as Backstage (Pohl et al., 2011), backchan.nl (Harry, Green, \& Donath, 2009), and Hotseat, (Aagard et al., 2010). These research studies are examples of how educational settings have become the focus of backchannels, specifically with attempts at increasing engagement and interactivity in large venues.

Although research on backchanneling began in these large venues, some research has focused on the educational benefit of backchannel discussions in smaller classroom settings (Clesson, 2011; Poleon \& Krishnan, 2013; Toledo \& Peters, 2010; and Vogler, et. al, 2013). For example, in Clesson's (2011) study of backchannel discussions with 160 high school students across 14 classes, she found $78 \%$ of students preferred backchannel discussion over live discussion, 66\% felt more anxious in live discussions than in the backchannel, and 69\% felt most engaged in the backchannel rather than the live discussion. Furthermore, the study found overall engagement, as measured by participation, resulted in a 3:1 ratio when comparing virtual backchannel to live discussion contributions.

While cognitive overload was a concern identified in Chan et al.’s (2006) study, Toledo and Peter's (2010) study found that backchanneling leads to an increase in student engagement as it provides students with "a greater sense of ownership over [their] learning" (p. 83). In this qualitative study with 17 education professionals, including teachers, library specialists, and IT directors, the researchers conducted interviews with the participants and concluded that the digital environment provided a safe place for students who tend to melt into the background to find their voices and contribute to class discussion. But perhaps their most relevant finding in terms of our own study was that students were able to make connections to both texts and their lives through the use of the backchannel.

Finally, in Vogler et al. (2013), eight participants in a graduate-level seminar engaged in a face-to-face discussion around assigned texts, then moved to a computer lab to have a synchronous discussion around the same texts. Using video recordings and screen captures as data sources for the study, the researchers were able to analyze participants' engagement in the online discussion. The findings from the study indicated that the literacy processes of the participants varied; however, there were "many available paths to contribute effectively and to develop understandings from a classroom discussion that takes place online" (Vogler et al., 2013, p. 232). Most importantly, their findings provide further evidence for what we know about the "personalizing impulse" (Sipe, 2008) that takes place when individual readers construct personal meaning and how personalizing contributes to co-constructed knowledge in a social setting. According to Sipe (2008), readers have a tendency to want to personalize or connect to a story. Therefore, the personalizing impulse is the urge to "forge links between the concepts, assumptions, narrative trajectory, and thematic meanings evoked or invited by the text and the reader's (or listener's) own psychic world” (p. 190).

Backchanneling may resemble the synchronous discussion described by Vogler, et al.; however, there are differences worth noting. Most notably, in the Vogler, et al. study, the conversations took place in two distinct parts, whereas in the backchanneling approach front and backchannel conversations are taking place simultaneously. In the study by Vogler and her colleagues, there was no indication of the level of participation in the face-to-face discussion. In a typical face-to-face discussion, not everyone in the classroom is participating in the conversation. However, in structuring a front and backchannel discussion, the front channel has a very specific purpose that contributes to input among all participants. Additionally, there are distinct differences between the asynchronous online discussions dominating the current research and backchanneling. 
A backchannel discussion typically takes place in the classroom at the same time as a live discussion, and a sense of community among the learners already exists. However, in an asynchronous discussion, participants are not present in the same physical space and likely post their responses at different times throughout a given period of time.

\section{Reader Response as a Theoretical Framework}

The work of reader-response theorists, particularly that of Louise Rosenblatt (1978), supports the notion that meaning-making will take place through the participation in backchannels as participants read and respond to other participants' ideas. Rosenblatt's transactional theory posits that meaning making occurs when a reader transacts with a text. Similarly, the work of Langer (2000) supports Vygotsy's (1978) notion that learning is socially based and suggests that ways of thinking are developed from the socially based experiences such as classroom discussions. Langer (1989) describes her view of reading as envisionment building. In this view, readers' understanding of text grows over time as the reading progresses. Like Rosenblatt, Langer believes that readers make meaning through stances. Rosenblatt describes a reader's purpose as existing along a continuum of aesthetic and efferent stances. With an aesthetic stance each reader brings different purposes and experiences to a text, therefore constructing their own meaning and feeling (Rosenblatt, 2004). Conversely, an efferent stance is when a reader's purpose is to identify or take away a specific piece of information. However, Langer (1989) indicates that these stances are "a series of relationships readers [take] toward the text, each adding a somewhat different dimension to the reader's growing understanding of the piece" (p. 8). These stances are recursive and help to enrich the reader's developing envisionments, or the understanding the reader has about a text at any one particular time. Backchanneling offers another way for readers to engage in that recursive process by providing a socially based experience that adds another "dimension to the reader's growing understanding of the text."

Sipe (2008) also provides theoretical insight for the present study. An expert in reader response theory, Sipe studied the responses of young children and theorized five types of talk that take place in a classroom setting: analytic, personal, intertextual, transparent, and performative. Analytic responses are defined by indications that the reader is making sense of the text, the language, the illustrations and visual matter - these may be evaluative, summarizing, critical resistance, speculations, questions, etc. Personal responses are noted when readers make connections to self. Intertextual responses indicate that readers are connecting one reading experience or text to another text. Transparent responses are defined by a response the reader makes that is not necessarily meant for the other channel participants-it's like talking back to the text. Finally, performative responses are noted when the reader says or does something that is meant for the other participants and is attention seeking.

Other researchers, such as Larson (2010), studying online response have grounded their studies in reader response theory and how readers comprehend during online discussions. Larson (2010) built upon Rosenblatt's transactional theory in her study of e-book reading and responding with 17 second graders in the Midwest. Response types include understanding the story, personal meaning-making, questioning, answering, and text features/evaluation. Although Rosenblatt, Langer, and Sipe were not studying readers' stances or meaning making in online environments, the process of response is similar, and these theorists provide the necessary theoretical underpinnings for reader response frameworks in digital spaces. 


\section{Methodology}

This study is grounded in practitioner research, which emphasizes insider research that systematically collects and reflects upon evidence of practice. This research approach fit the intent of our study in that our primary goal was to gather knowledge that would impact practitioners in the field and to study instructional approaches that could potentially transform our own teaching, as well as the future teachers we were working with (Anderson, Herr, \& Nihlen, 1994). In particular, we are interested in whether combining backchanneling with fishbowl discussions could contribute to students' understanding of texts. Fishbowl discussions, which are structured so that the majority of the class observes a small group of participants in a discussion, are advantageous because they are more easily managed than whole class discussions, offering the potential of deeper engagement. One disadvantage of this approach, however, is that only a few voices are heard. Can the inclusion of backchannels provide an effective integration of technology that allows more participants to enter the dialogue? In addition, as literacy researchers, we are particularly interested in how participants talk about written texts through face-to-face and online discussion. Thus, we explored the following research questions: What kinds of meaning making occurred when using backchannels in the classroom? What did the technology add to a traditional face-to-face classroom discussion? To answer these questions, we focused on data from transcribed discussions and transcripts from online chats.

\section{Participants and Data Collection}

Participants in this study consisted of undergraduate students at a Midwestern university. The group was made up of 19 preservice secondary teachers who were in the first semester of a yearlong internship in a professional development school (PDS) partnership. Their time was split between attending classes, including the general pedagogy and content literacy courses associated with the PDS, and working in their mentors' classrooms, where they would student teach full time in the spring semester. Robyn taught the group during the 2012-2013 school year. Both of us have used backchannel discussions in previous courses prior to this study. In the course used for this study, backchanneling was introduced early in the fall semester and took place three times throughout the semester.

The data presented in this article were collected in November, which means participants had experienced backchanneling at least two times prior to this discussion. This event was chosen as a representative case of the other instances backchanneling occurred in this class, as well as in another class where similar data were collected and analyzed. Findings across all events were similar.

The class was divided into four groups - three groups of four and one group of five. Two students were absent for this discussion. Each group was assigned their own backchannel site using TodaysMeet.com. Students in each group used their personal laptops to access the chat room. A representative from each group made up the center circle (the front channel). Each representative brought a laptop to the front channel discussion so group members in the backchannel could communicate with their front channel representatives. Backchannel groups only read the communication within their own chatrooms, keeping the four conversations in the backchannels separated from each other. The backchannel members sat in a circle surrounding the front channel. While all the students were present in the room, only those in the front channel communicated face-to-face. This discussion lasted just over an hour and focused on a chapter from their textbook, 
which discussed different approaches to designing instruction. In particular, the chapter introduced the concepts of direct instruction and cooperative learning, defining each concept, explaining the role of the teacher, and providing tips on how to best plan for each instructional approach.

Following each backchannel discussion, Robyn debriefed the discussion with students. The preservice teachers shared interesting ideas that arose during their individual discussion, allowing time to draw connections between discussions and ask questions of other groups. In addition to continuing the discussion about the text, this time also allowed the class to discuss the backchannel process. It was through debriefings like this that changes were made to future backchannel discussions.

In order to manage the collection of the data, a password protected digital folder was created and shared between researchers. Transcripts from the digital backchannels were saved as PDF files, and front channel discussions and whole class debriefings were recorded and transcribed. For this analysis, we used the transcripts from the front and backchannel discussions.

\section{Data Analysis}

To begin our coding process, we first engaged in exploratory coding, assigning provisional codes (Saldaña, 2009) in order to determine the best approach to understanding our data. We began this process by assigning codes used in previous backchannel studies (Chan et al., 2006). In their study, Chan et al. identified descriptors of types of comments made during backchannel conversations: entry/exit, germane to text, indirectly related to text, about text, and social. After using this coding system on the first few pages of a transcript, we discovered that this approach did not provide us with enough information about how the backchannel contributes to participants' transactions with various texts. Next, we attempted to code our data using the reading strategies identified by literacy researchers (e.g. Palinscar \& Brown, 1986; Schoenbach, Greenleaf, Cziko, \& Hurwitz, 1999): predicting, clarifying, questioning, and summarizing. After coding a few pages of the same transcript, we realized that while these codes provided us with more insight into how the participants made meaning, we felt like we were still missing information about the impact of social interaction in both the front and backchannels that contributed to meaning making. Thus, after careful consideration of available frameworks that could help us generate the answers to our research question (Saldaña, 2009), we settled on Sipe's (2008) types of response, which he developed through an analysis of children's verbal responses to texts. We wanted to see the parallels between an online talk and a face-to-face talk. Additionally, Sipe's categories of talk align with our reader response framework and our research focus to determine the kinds of meaning making that took place in participants' discussion of the assigned reading.

Because our intent was to build upon Sipe’s (2008) work with adult learners rather than children and in an online forum, as well as a verbal one, it made sense to provisionally code the data using his categories of talk: analytic, personal, intertextual, transparent, and performative (Miles \& Huberman, 1994). Once it became evident that these codes did provide us with insights into participants' meaning making, we individually read and coded the transcripts in order to ensure reliability in coding (Saldaña, 2009). As we analyzed our data, we met regularly to discuss our findings. During these meetings, we also reviewed each other's findings and discussed any discrepancies in codes in order to reach a consensus. These conversations allowed us to deepen our understanding of the categories of talk, as well as how the students used these types of talk to express their meaning making and create new meaning through social interaction. In addition, these meetings allowed us to expand our codes in order to explain a type of talk not identified by 
Sipe (2008)—negotiation, which we defined as the type of talk necessary to define, negotiate, and respond to the demands of an online space.

\section{Findings}

While we found evidence of all types of talk in the transcripts, analytical talk was prevalent in the conversations. This finding is consistent with Sipe's study in which analytic talk was present 73\% of the time. Table 1 illustrates the percentage of type of talk for each of the small groups.

Table 1. Undergraduate percent of type of talk within each channel

\begin{tabular}{|c|c|c|c|c|c|}
\hline Type of Talk & Front & Back 1 & Back 2 & Back 3 & Back 4 \\
\hline Negotiation & 0 & 10 & 4 & 26 & 22 \\
\hline Analytic & 58 & 67 & 70 & 58 & 38 \\
\hline Personal & 35 & 18 & 15 & 2 & 8 \\
\hline Intertextual & 2 & 5 & 7 & 6 & 5 \\
\hline Transparent & 0 & 0 & 0 & 0 & 0 \\
\hline Performative & 5 & 0 & 4 & 8 & 27 \\
\hline
\end{tabular}

Looking across the five discussions analyzed in this study-one front channel and four backchannels - analytical talk occurred most frequently in all of the discussions. These findings suggest backchannels can support close readings of texts. In the following sections, we will discuss findings from Table 1 in greater detail.

\section{Analytical Meaning Making}

In his discussion of analytical responses to literature, Sipe (n.d.) compared this type of talk to what New Critics call close reading. As students engage in analytical talk, they are paying close attention to the text itself-discussing how the author presents information, defines key terms, and structures the argument in order to determine what the text means.

Much of the defining talk revolved around trying to understand the concepts of direct instruction and cooperative learning, which are the focus of the chapter they were discussing. In the front channel, to begin the conversation on direct instruction, Bailie referred to a quote in the textbook that contrasts the image of teachers who use direct instruction as grim and authoritarian with teachers who are actually more flexible and allow for more freedom in the classroom. She elaborated on her interpretation of this quote by stating, “... direct teaching can be very beneficial to students if, you know, the teacher has those characteristics of being more concerned, and I think it shows the basis of teaching is relationships.”

While this analysis of a quote from the text helped begin the conversation in the front channel, it also helped propel the conversations in the backchannels. For example, in Backchannel Room 4, Samantha built directly on this discussion, referring her group back to the book, as well: "according to the book, direct teaching is teacher centered and requires the teacher to be a good motivator." This comment from Samantha prompted the group to spend time discussing the role of motivation. Conversely, in Backchannel Room 2, rather than focusing on motivation, the front channel's reference to the text began a discussion about the merits of direct instruction:

Brittany: Rarely teachers use direct teaching effectively. 
Maya: I think it also depends on the learner

Olivia: True, it turns into lectures and the students disengage

Maya: some students benefit from direct teaching.

Brittany: Yep, especially considering what Anna just said; students can only really listen for 20 mins.

Maya: direct teaching allows teachers to explain how to do something in detail

Maya: and offers students a chance to work with guided practice

Olivia: I think it's important to incorporate both kinds of teaching [direct instruction and cooperative learning] to account for all learners, but do it right

Brittany: But I do agree with Maya. Some material is best taught directly. I think it lends itself to math and science well.

Olivia: for example, don’t just lecture. make it more interactive

As this discussion illustrates, participants drew upon multiple resources to define direct teaching. Through their reading of the text itself, as well as the front channel's interpretation of the chapter, this backchannel worked together to create an understanding of direct teaching that coincides with their beliefs about teaching. Defining direct teaching and cooperative learning was vital to their understanding of the texts because they were new to the teaching profession and had very little time in front of a class of students. Thus, they used these discussions as a way to better understand two common teaching approaches.

In addition to analyzing the content of the text, participants also spent a brief amount of time discussing the authors' decisions in structuring the texts. At one point during their attempts to make sense of the strategies of direct teaching and cooperative learning, Backchannel Room 3 sent the following message to the front channel: “@Toby, I felt that as our book discussed direct teaching, they tried to incorporate aspects of cooperative learning in its implementation." This note prompted the front channel to discuss how the authors attempted to redefine direct teaching for readers, leading to a discussion of misconceptions about direct teaching. In this case, the structure of the authors' arguments helped the students achieve better clarity about a concept, but this is not always the case. There was much disagreement in all of the discussions about the jigsaw strategy, a strategy where students meet with other students to become experts on a topic and then form small groups where each student can teach the new information to their other group members.

At one point, Piper commented, "I think it sounded valuable, but I got confused reading it.” While this was not a direct critique of the structure itself, it did offer a slight rebuke to the way the authors structured their description of the strategy. In this way, Piper acknowledged that the text had not offered her the support she needed to better understand the topic, and so, she requested assistance from her group.

\section{Personal Meaning Making}

While analytical talk may be aligned with close reading, personal talk is more closely compared to the reader response movement (Sipe, n.d.). In this vein, discussions turn to life-to-text and textto-life connections, allowing readers to better understand the text through their own lived experiences. At the same time, readers are able to better interpret and evaluate their experiences by examining them through the lens provided by the text. Personal talk was also threaded throughout the conversations. Sipe distinguished between two types of personal talk: life-to-text connections and text-to-life connections. In life-to-text connections, readers look to how the texts mirror their own lives. Conversely, text-to-life experiences occur when readers use the text to 
better understand their own lives. Like Sipe, we found that most personal connections made in our study were life-to-text, with participants connecting the texts to current and future contexts.

Life-to-text connections. Much of the participants' contexts at the time of the study revolved around their experiences as a student. In the front channel, the preservice teachers described their experiences in high school science labs to try to make sense of cooperative learning. Similarly, in Backchannel Room 1, as her group attempted to understand the jigsaw strategy, Macy explained that she had experienced the strategy in many of her history classes. This prompted the front channel to share Macy's experience and question whether anyone in that discussion had similar experiences. When Brittany responded that she had also experienced jigsaw in history classes in high school, the group took the opportunity to share other experiences working in cooperative groups. Ultimately, because of these future teachers' own experiences working in groups, the undergraduates remained skeptical of the jigsaw approach, with each person's story confirming their initial skepticism.

Text-to-life connections. In addition to life-to-text connections, Sipe (2008) also found that there were instances where participants used the story to better understand a circumstance in their own lives. Sipe observed that while these types of connections were rare, when they occurred, they were "deeply meaningful for the children” (p. 160). These types of connections were also rare in our study, but they did occur. Backchannel Room 4 was the only group to make these types of connections, which was somewhat ironic since, as we will discuss shortly, much of their later conversation illustrated more performative talk. Yet, as Samantha discussed the role of motivation in direct teaching, she reflected somewhat fearfully, "what if I am a bad motivator??” Her use of two question marks reflects how deeply she worried about this question. Further evidence of this worry came in her next statement, “is that setting my classroom up for failure?" This brief interlude demonstrated that a piece of the text struck a chord within Samantha, and while the group did not spend much more time discussing motivation after Samantha shared her fears, her statements did demonstrate that she was actively thinking about the text due to her personal connections.

\section{Intertextual Meaning Making}

Similar to personal talk, intertextual talk requires readers to make connections. In this case, however, readers are using their understanding of other texts to make meaning of the text they are discussing. All five of the discussions referenced other texts, pointing to the impact of experience. Without lived experiences, the preservice teachers instead drew upon other texts to aid in their interpretations.

Students made both associative links, commenting on similarities between texts, and analytical links, discussing similarities and differences between texts, in order to better understand the text being discussed (Sipe, 2008). The most notable associative link began in Backchannel Room 4 when Justin noted, “Everytime I hear jigsaw I think of the Saw movie series.” Ironically, the same idea emerged in Backchannel Room 3 just a minute later, when Addison remarked, "jigsaw also sounds too much like a horror movie." Although she did not state it as directly as Justin, it was likely a similar awareness of the Saw movie franchise that sparked Addison's connection, as well. Aside from the word "saw," on the surface these two topics have very little in common, leading one to expect that this connection had little impact on making meaning from the 
text. Surprisingly, this was not the case. Diana in the Front channel, who was monitoring Addison's group, picked up on this association and translated the reference into an opportunity to use the horror movie franchise as a way to analyze the text they were discussing:

I think someone said that jigsaw sounds too much like a horror movie. I mean, I can see that. I can see, like you know, I think it's scary when we give up control to the students. Like, we're still obviously monitoring and making sure they stay on task, but we all get scared when we give up that sense of control because we're all first-year teachers, and that's scary.

This observation prompted similar discussions in the other backchannels, pointing to the impact that even seemingly unrelated textual connections can aid in the meaning making process.

In addition to the horror movie discussion, two other intertextual connections were made. The first was a brief mention in the front channel of an episode of The Simpsons as Brady attempted to better understand the idea of presentation stage, a concept presented in the textbook. The other intertextual connection was in Backchannel Room 3 when Joel asked whether or not the section on direct teaching was promoting moving students from guided to independent practice. Addison pointed him to the other book used in the course to help guide this discussion. Addison's use of intertextual connections provided the group with a resource to better make sense of the text they were discussing, and while neither group spent a lot of time discussing the other text, it showed an awareness of how other texts can be used in the meaning making process.

\section{Performative Meaning Making}

Performative responses occur when readers use the text as a springboard for playful interaction. More than likely, it is this type of response-particularly in an online forum-that often leads to the claim that students are distracted and disrupting meaning making. Sipe (n.d.) argued, however, that these types of responses can be considered as playing with the text in order to allow readers to explore their own creativity. Performative talk was found in four of the five discussions. With the exception of one discussion, the performative talk was a direct result of a topic raised by the text, and the dialogue quickly moved back to other types of talk. One group used performative talk quite frequently, often straying from the text. This was not surprising given the dynamics of that particular group. However, the group's discussion was still dominated by analytical talk, suggesting that even with performative talk, meaning making still occurred.

With the exception of Backchannel Room 4, most of the performative talk were brief interludes such as Olivia's response to an image Brittany posted of a saw during the horror movie discussion: "LOL ahhhhhhhhh!!” These types of performative comments were quickly forgotten as the group continued with the discussion of more serious topics raised in the text. In Backchannel Room 3, a slightly longer performative discussion wrapped up their conversation. Gage introduced this discussion as a response to the group's comments about giving students more control through cooperative learning.

Gage: I still plan on ruling with a IRON FIST. It's all about me and what i want. me me me me me me.

Gage: hahahaha. jk...

Addison: @Gage, you are at the wrong school to be ruling with iron!

Gage: Gotta rule my wildcats somehow.

Addison: Like a cat, meow 
Just as Sipe described, this exchange showed Gage playing with the ideas expressed through the text and the resulting discussion. Addison picked up on this playfulness, referencing the mascot of the school where she was completing her clinical placement (the Ironmen) and pointing out that Gage did not have the privilege of an iron fist because he did not work in her school. Despite this playfulness, Gage was making a commentary on the discussions that he took part in-in both his backchannel room and the front channel via his questions to Diana. His references to the "IRON FIST" and "me me me me me me" directly contrasted his support of cooperative learning throughout the rest of the discussion, as well as in his work outside this discussion. This suggests that he was subversively making fun of the fear of giving up control expressed by others when discussing cooperative learning.

While Gage's performative talk represented a different form of meaning making, the performative talk that occurred at the end of Backchannel Room 4's discussion took yet another form. After a discussion that was primarily analytical, it was obvious the group began to tire of the discussion and decided to take control of the front channel's discussion. They began this revolt by prompting their front channel representative to heckle one of the members of the front channel. When she did not respond, Calvin prompted, “@Erin-you aren’t doing your job if you don’t be our voice!" Then, Samantha made their agenda explicit by stating, "let's change the direction of the center convo." It was at this point of the conversation when it became clear that despite their playful attempts to hijack the conversation, there was a true desire to change the subject, with Samantha referencing a fairytale unit discussed in the text. Although some people may view performative talk as "off task" or "inappropriate," we tend to agree with Sipe (2008) when he explained that performative talk is another form of meaning making. For us, the performative talk served a clear purpose and assisted in meaning making that was sustainable.

\section{Transparent Meaning Making}

The final category of talk identified by Sipe (2008) is transparent where the line between the text and the reader is blurred. This type of talk is often reserved for fiction where readers become so immersed in the story they figuratively step into the action for a moment in time. While we did find transparent talk occurring briefly in other backchannel discussions, there was no evidence of this type of talk on that particular day. It was likely that these preservice teachers were not engaged enough with the topic of direct instruction and cooperative learning to lose themselves in the text.

\section{Negotiating the Backchannel}

During our analysis, it quickly became evident that in addition to the types of talk identified by Sipe (2008), a sixth type of talk is necessary for effective discussion to occur in an online forum. We name this type of talk negotiation. The reliance on typed text to guide the discussion means that nonverbal cues typically found in verbal communication are absent, leading to the need to negotiate the space where the conversation is taking place. In this time of negotiation, participants must define and react to the digital space in order for meaning making to occur. So while negotiation in and of itself is not a meaning-making type of talk, it is a necessary type of talk for discussants to be able to participate in the other five types of responses. This necessity was made evident by the existence of negotiation across all the backchannels.

Negotiation served four purposes: greeting each other, defining the space, taking care of technology needs, and encouraging each other's participation. Greetings took on many forms, 
including the traditional "Hello!" and "Hey" as well as the more colloquial "Holler" and "waddup." At times, rather than entering the conversations with a greeting, members began by trying to define the space, questioning, "is this the right place...?” Defining the space also extended beyond these types of queries. Discussants took time to establish communication rules. This was particularly the case for the Backchannel Rooms 3 \& 4, where they identified the “@” as a way to indicate who they were addressing.

Although it happened in only one chat room, another very necessary negotiation for Backchannel Room 4 occurred when the group noticed that Samantha was suddenly absent from their conversation. When Justin asked Samantha if she was having issues, she responded with "My internet cuts out every so often, so I have to keep refreshing or I don't see the convo :(.” Because they were relying on technology to communicate, it was important for them to let their group members know when the tool posed challenges. Finally, they also used the space to offer encouragement to their group members. This was most evident when they were speaking to or referencing the members in the front channel. This generally meant speaking directly to their representatives in the front channel, such as when Addison posted, "Represent Diana!" when their conversations began. As with performative talk, some may view negotiation talk as "off task" or irrelevant to meaning making. However, we found that negotiation was necessary for response in a digital space and also helped to build community within each of the small groups.

\section{Discussion}

A recurring theme within discussions focused on technology is whether or not technology is a necessity or a nuisance. Can it impact student learning? Does it prepare students for future contexts? Or is it simply a flashy new way to do what has always been done-perhaps even serving more as a distraction? The answer, of course, is not simple. If used in an artificial manner, technology-like any educational tool-can distract from learning objectives rather than enhancing student understanding. Yet, in the case of this study, students were able to use the technology to engage in multiple conversations about text in a manner that would not be possible in a traditional classroom set-up. The cognitive demands of focusing on two conversations at once (front and back channels) did not appear to have an adverse effect. While participants did not always follow both conversations simultaneously, they were able to alternate between conversations. For the backchannel, the front channel primarily served as a launching point for conversation.

Through the use of the backchannel, students were able to raise questions that immediately occurred to them - calling upon their peers rather than just the teacher to socially construct their understanding of the texts. This dynamic positions both the teacher and the students as coconstructors of knowledge. As witnessed across all discussions, participants demonstrated literacy skills of analyzing and critiquing. They vacillated between close reading and personal response, providing a well-rounded reading experience that increases the likelihood of a meaningful reading experience. Importantly, they also built upon each other's experiences in order to determine how best to apply the readings to their personal situations.

In traditional teacher-led class discussions, the opportunities to engage each student in a discussion of text are diminished as more vocal students often dominate the dialogue, while quieter students are content to sit back and let them. Our study demonstrates that all students were able to use the backchannel as an opportunity to increase their participation. While some were definitely more active than others, all regularly participated, pointing to the potential of backchannels as one 
approach to increasing learning. Like Toledo and Peter's (2010) work, our study points to backchanneling as a way to increase engagement in class discussion.

By capturing the front channel discussions through audio recordings and transcriptions and the backchannel discussions through archived online chats, we were able to compare conversations across groups in order to explore how each group shaped their talk using common texts. As the previous sections indicate, our analysis illustrates that participants were able to draw upon the texts, themselves, and their peers to engage in meaningful talk about the ideas presented in the texts. Further, we were able to move students away from passive recipients of information via technology to active producers of knowledge using free online tools.

These findings are significant given the ongoing dialogue occurring within the field. The educational landscape is under a barrage of forces, making it increasingly likely that tomorrow's classroom will bear little resemblance to today's. Rapid changes in technology prompt questions designed to explore the role technology can and should play in classroom instruction. Using backchannels with preservice teachers can not only increase their engagement with the ideas presented in class, it can also model appropriate ways these future teachers can integrate technology into their own classrooms. Perhaps most importantly, they have seen first-hand how their future students can use technology to create new understandings, helping them to be active rather than passive learners-leading to the transformation technology researchers have advocated for when examining teaching and learning (Hughes et al., 2006; Puentedura, 2006). 


\section{References}

Aagard, H., Bowen, K., \& Olesova, L. (2010). Hotseat: Opening the backchannel in large lectures. EDUCAUSE Quarterly, 33(3). http://www.educause.edu/ero/article/hotseat-openingbackchannel-large-lectures.

Anderson, G. L., Herr, K. L., \& Nihlen, A.S. (1994). Studying your own school: An educator's guide to qualitative practitioner research. Thousand Oaks, CA: Corwin Press.

Chan, S. Mitnick, S., \& Yardi, S. (2006). Class chat: A tool for visualizing backchannel discussions. (Unpublished Master's Project). School of Information Management and Systems, University of California, Berkeley.

Clesson, K. M. (2011). Backchanneling, communication apprehension, and student engagement in discussion-based high school classes (Unpublished doctoral dissertation). Illinois State University, Normal, IL.

Cope, B., \& Kalantzis, M. (2009). "Multiliteracies”: New literacies, new learning. Pedagogies: An International Journal, 4(3), 164-195.

Garrison, R., Anderson, T., \& Archer, W. (2000). Critical inquiry in a text-based environment. The Internet and Higher Education, 2(2/3), 87-105.

Guernsey, L. (2003, July 24). In the lecture hall, a geek chorus. The New York Times, p. G1.

Harry, D., Green, J., \& Donath, J. (2009, April). Backchan.nl: integrating backchannels in physical space. In Proceedings of the SIGCHI Conference on Human factors in Computing Systems (pp. 1361-1370). ACM.

Hughes, J., Thomas, R. \& Scharber, C. (2006). Assessing technology integration: The RAT replacement, amplification, and transformation - framework. In C. Crawford, R. Carlsen, K. McFerrin, J. Price, R. Weber \& D. Willis (Eds.), Proceedings of Society for Information Technology \& Teacher Education International Conference 2006 (pp. 1616-1620). Chesapeake, VA: Association for the Advancement of Computing in Education (AACE).

Jacobs, N. \& McFarlane, A. (2005), Conferences as learning communities: Some early lessons in using 'back-channel' technologies at an academic conference - distributed intelligence or divided attention? Journal of Computer Assisted Learning, 21, 317-329. doi:10.1111/j.13652729.2005.00142.x

Johnson, S. B. (2009, June15). How Twitter will change the way we live (in 140 characters or less). Time, 173(23), 32-37.

Langer, J. A. (2000). Literary understanding and literature instruction (Report Series 2.11). Albany, NY: Center for the Learning and Teaching of Literature. 
Langer, J. A. (1989). The process of understanding literature (Report Series 2.1). Albany, NY: Center for the Learning and Teaching of Literature.

Lankshear, C. \& Knobel, M. (2011). New literacies: Everyday practices and social learning. London, UK: McGraw-Hill.

Larson, L. (2010). Digital readers: The next chapter in e-book reading and response. The Reading Teacher, 64(1), 15-22. doi:10.1598/RT.64.1.2

Maftoon, P. \& Ziafar, M. (2013). Effective factors in interactions with Japanese EFL classrooms. Clearing House: A Journal of Educational Strategies, Issues and Ideas, 86(2), 74-79.

Miles, M. B. \& Huberman, A. M. (1994). Qualitative data analysis: An expanded sourcebook. Los Angeles, CA: Sage.

Mishra, P. (2008). Microblogging in the classroom II. Retrieved from http://punya.educ.msu.edu/2008/11/20/microblogging-in-the-classroom-ii/ The New London Group. (1996). A pedagogy of multiliteracies: Designing social futures. Harvard Educational Review, 66(1), 60-93.

Palinscar, A. S. \& Brown, A. (1986). Interactive teaching to promote independent learning from text. Reading Teacher, 39(8), 771-777.

Pohl, A., Gehlen-Baum, V., \& Bry, F. (2011). Introducing backstage: A digital backchannel for large class lectures. Interactive Technology and Smart Education, 8(3), 186-200.

Poleon, E., \& Krishnan, J. (2013). Digital Backchanneling: A strategy for maximizing engagement during a performance-based lesson on Shakespeare's Macbeth. Teaching English with Technology, 4, 38-48.

Puentedura, R. (2006). Transformation, Technology, and Education. Presentation given August 18, 2006 as part of the Strengthening Your District Through Technology workshops, Maine, US. Retrieved from http://hippasus.com/resources/tte/part1.html.

Rosenblatt, L. (1978). The Reader, the text, the poem: The transactional theory of the literary work. Carbondale, IL: Southern Illinois University Press.

Rosenblatt, L. M. (2004). The transactional theory of reading and writing. In R. B. Ruddell, \& N. J. Unrau (Eds.), Theoretical Models and Processes of Reading (pp. 1363-1398). Newark, DE: International Reading Association.

Saldaña, J. (2009). The coding manual for qualitative researchers. Los Angeles, CA: Sage.

Schwier, R. A., \& Seaton, J. X. (2013). A comparison of participation patterns in selected formal, non-formal, and informal online learning environments. Canadian Journal of Learning and Technology, 39(1). Retrieved from http://www.cjlt.ca/index.php/cjlt/article/view/709/355 
Schoenbach, R., Greenleaf, C., Cziko, C. \& Hurwitz, L. (1999). Reading for understanding: A guide to improving reading in middle and high school classrooms. San Francisco, CA: JosseyBass.

Shirky, C. (2002, Dec. 26). In-room chat as a social tool. Published in OpenP2P.com. Retrieved July 12, 2009, from http://openp2p.eom/lpt/a/3071.

Sipe, L. (2008). Storytime: Young children's literary understanding in the classroom. New York, NY: Teachers College Press.

Sipe, L. (n.d.). Young children's responses to picture storybooks: Five types of literary understanding [PDF document]. Retrieved from http://literatura.gretel.cat/sites/default/files/barcelona_lecture.pdf.

Toledo, C. \& Peters, S. (2010, May). Educators’ perceptions of uses, constraints, and successful practices of backchanneling. In Education: Technology \& Social Media (Special Issue, Part II) 16(1). http://ineducation.ca/article/educators-perceptions-uses-constraints-and-successfulpractices-backchanneling.

Vogler, J. S., Schallert, D. L, Park, Y., Song, K., Chiang, Y. V., Jordan, M. E., Lee, S., Cheng, A. J., Lee, J., Park, J., \& Sanders, A. (2013). A microgenetic analysis of classroom discussion practices: How literacy processes intermingle in the negotiation of meaning in an online discussion. Journal of Literacy Research, 45(3), 211-239.

Vygotsky, L. S. (1978). Mind in society: The development of higher psychological processes. Cambridge, MA: Harvard University Press.

White, S. (1989). Backchannels across cultures: A study of Americans and Japanese. Language in Society, 18(1), 59-76.

Yngve, V. H. (1970). On getting a word in edgewise. In papers from the 6th Regional Meeting of the Chicago Linguistics Society, pp. 567-577. Chicago, IL: CLS. 